\title{
Intermittent pneumatic compression prevents venous stasis in the lower extremities in the lithotomy position
}

\author{
[Une compression pneumatique intermittente prévient l'insuffisance veineuse aux \\ membres inférieurs en position gynécoloqique]
}

Shinji Kohro MD PhD, ${ }^{*}$ Michiaki Yamakage MD PhD, $†$ Toshiyuki Takahashi MD, ${ }^{*}$ Mitsu Kondo MD, * Koichi Ota MD PhD, ${ }^{*}$ Akiyoshi Namiki MD PhD†

Purpose: To investigate the interactions of a new lithotomy positioning device (LPD) with two intermittent pneumatic compression (IPC) devices by measuring femoral venous flow velocity.

Methods: Subjects were divided into three groups: I) supine position as a control, 2) lithotomy position using a conventional LPD, and 3) lithotomy position using a new LPD, Levitator ${ }^{T M}$. These three groups were further divided in two according to the type of IPC device used: AV-impulse ${ }^{\text {TM }}$ (rapid IPC) and SeQuel ${ }^{\text {TM }}$ (standard IPC). Peak femoral venous flow velocity was measured by using an ultrasonic echo diagnostic device. Data were analyzed by one-way ANOVA with Fisher's test or by the unpaired two-tailed t test.

Results: Moving to the conventional lithotomy position from the supine position, venous flow velocity was decreased by $38 \%$ in both IPC device groups. Even when the new LPD was used to support the lithotomy position, the flow velocity was decreased by $24 \%$, but the velocity was significantly higher than in the conventional lithotomy position. Both rapid and standard IPC devices increased flow velocity to $77 \%$ and $107 \%$ (first compression) and to $71 \%$ and $84 \%$ (fifth compression) of the control values during compression, respectively. In the lithotomy position group using the new LPD, similar increases in flow were seen with the use of IPC devices.

Conclusion: Both rapid and standard IPC devices are useful for maintaining venous flow of the lower extremities in the lithotomy position.
Objectif: Rechercher les interactions d'un nouvel appareil pour position gynécologique (APG) comportant deux dispositifs à compression pneumatique intermittente (CPI) en mesurant la vitesse circulatoire de la veine fémorale.

Méthode : Les sujets ont été divisés en trois groupes: I) témoins en décubitus dorsal, 2) position gynécologique avec un APG traditionnel et 3) position gynécologique avec un nouvel APG, Levitator ${ }^{\mathrm{TM}}$. Ces trois groupes ont été subdivisés en deux selon le type de CPI utilisée : AV-impulse ${ }^{\mathrm{TM}}$ (CPI rapide) et SeQuel ${ }^{\mathrm{TM}}$ (CPI régulier). La vitesse circulatoire fémorale maximale a été mesurée grâce à l'échographie diagnostique. Les données ont été soumises à l'analyse de variance à une voie et le test de Fisher ou le test bilatéral pour série non appariées.

Résultats : En passant du décubitus dorsal à la position gynécologique traditionnelle, la vitesse circulatoire veineuse a diminué de $38 \%$ avec l'utilisation des deux types de CPI. Même avec le nouvel APG, la vitesse circulatoire a baissé de $24 \%$, mais elle a été significativement plus élevée qu'en position gynécologique traditionnelle. Les deux dispositifs de CPI, rapide et régulière, ont fait respectivement augmenter la vitesse circulatoire à $77 \%$ et $107 \%$ (première compression) et à $71 \%$ et $84 \%$ (cinquième compression) des valeurs témoins pendant la compression. Avec le nouvel APG, des augmentations similaires ont été observées avec l'usage des deux dispositifs de CPI.

Conclusion : Les deux dispositifs de CPI rapide et régulière peuvent maintenir une vitesse circulatoire veineuse des membres inférieurs en position gynécologique.

From the Departments of Anesthesia, Ebetsu Municipal Hospital, * Ebetsu, and the Sapporo Medical University, $†$ School of Medicine, Sapporo, Hokkaido, Japan.

Address correspondence to: Dr. Michiaki Yamakage, Department of Anesthesiology, Sapporo Medical University, School of Medicine, South 1, West 16, Chuo-ku, Sapporo, Hokkaido 060-8543, Japan. Phone: +81-11-611-2111, ext. 3568; Fax: +81-11-631-9683; E-mail: yamakage@sapmed.ac.jp

Supported in part by an incentive grant (Y-058, 1999) for research from the Hokksaitec Foundation, Sapporo, Japan.

Accepted for publication October 1, 2001.

Revision accepted November 16, 2001. 


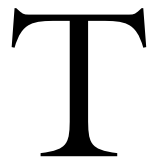

HE conventional lithotomy position with fixation of both knees may interrupt venous flow of the lower extremities and cause deep venous thrombosis, leading to pulmonary embolism. ${ }^{1}$ A new device (Levitator ${ }^{\mathrm{TM}}$; Skytron, Grand Rapids, MI, USA) that supports the lower extremities at the heels and calves in the lithotomy position has recently become available. We hypothesized that this new lithotomy positioning device (LPD) would prevent venous stasis of the lower extremities because it avoids compression of the popliteal fossa. On the other hand, two intermittent pneumatic compression (IPC) devices, the high-pressure, rapid-inflation, AV-impulse ${ }^{\mathrm{TM}}$ (Novamedix, Hampshire, UK), and a standard, low-pressure, slowinflation, SeQuel ${ }^{\mathrm{TM}}$ (Kendall, Mansfield, MA, USA) have been reported to be effective in preventing deep venous thrombosis. ${ }^{2-5}$ However, their effectiveness is still controversial. ${ }^{6-9}$ To clarify the interactions between position and IPC devices, we compared the effects of these devices on femoral venous flow velocity in the supine and lithotomy positions.

\section{Methods}

Thirty-six volunteers were enrolled in this study. They were randomly divided into three groups according to position: 1) supine position, 2) lithotomy position using a conventional LPD that fixes both knees, and 3 ) lithotomy position using a newly developed LPD that supports the lower extremities at the heels and calves. These three groups were further divided into two groups according to the type of IPC device used: rapid or standard. Thus, six volunteers were included in each group. While both soles of each volunteer were compressed for three seconds $(130 \mathrm{mmHg})$ at a $0.3-\mathrm{Hz}$ interval during rapid IPC, both legs from ankles to thighs were compressed by the standard IPC device, which has a six-chambered cuff applying 45 $\mathrm{mmHg}$ for $12 \mathrm{sec}$ sequentially, followed by a $60-\mathrm{sec}$ noncompression period. Peak femoral venous velocity was measured noninvasively at the common femoral vein $1 \mathrm{~cm}$ above the saphenofemoral junction by using an ultrasonic echo diagnostic device, FF sonic UF$8800^{\mathrm{TM}}$ (Fukuda Denshi, Tokyo, Japan). ${ }^{0}$ The venous flow velocity in the supine position was measured as a control in all groups. In the lithotomy position groups (45 and 90 angles at hip and knee joints, respectively), the venous flow velocity was also measured in the lithotomy position with or without the use of each IPC device.

Data were analyzed by one-way ANOVA with Fisher's test or by the unpaired two-tailed t test. $P$ $<0.05$ was considered significant.

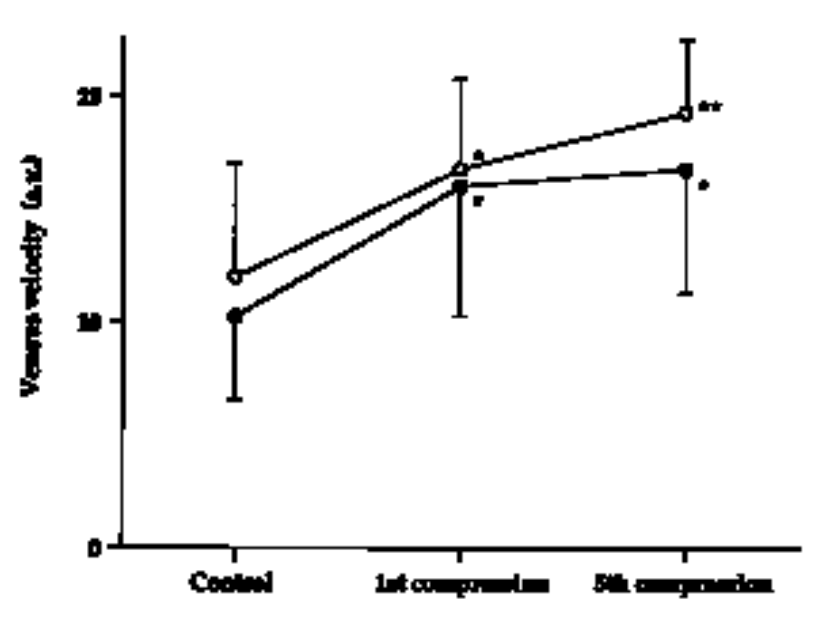

FIGURE 1 Changes in maximum femoral venous flow velocities by using rapid (closed circles) and standard (open circles) intermittent pneumatic compression in the supine position. Data are expressed as mean $\pm \mathrm{SD}, n=6$ at each point [arbitrary units; a.u.]. ${ }^{*} P<0.05 ;{ }^{*} P<0.01$ vs control.

Results

In the supine position, the mean $( \pm \mathrm{SD})$ flow velocity of the common femoral vein in the volunteers was $10.8 \pm 3.5$ arbitrary units. Under this condition, rapid IPC significantly increased maximum femoral venous flow velocity by $59 \%(P<0.05)$ during the first compression and by $63 \%(P<0.05)$ during the fifth compression (Figure 1). Standard IPC also increased venous flow velocity during the first and fifth compressions by $44 \%(P<0.05)$ and by $68 \%(P<0.01)$, respectively. There was no significant difference between the flow velocities using these two devices.

When moving to the conventional lithotomy position (with fixation of knees) from the supine position, the maximum femoral venous flow velocity was decreased by $38 \%(P<0.05)$ in both IPC device groups (Figure 2A). When the lithotomy position was maintained with the new LPD without compression on the popliteal fossa, maximum femoral venous flow velocity was decreased by $24 \%(P<0.05$, Figure $2 \mathrm{~B})$. The difference in flow velocities with conventional lithotomy and the new LPD was statistically significant $(P<0.05)$. In the conventional lithotomy position (Figure 2A), both rapid and standard IPC significantly increased flow velocity to $77 \%$ and $107 \%$ $(P<0.01)$ of the control value and to $71 \%$ and $84 \%(P$ $<0.05$ ) of the control value during compression, respectively. In the new LPD group, both rapid and standard IPC significantly increased the flow velocity 


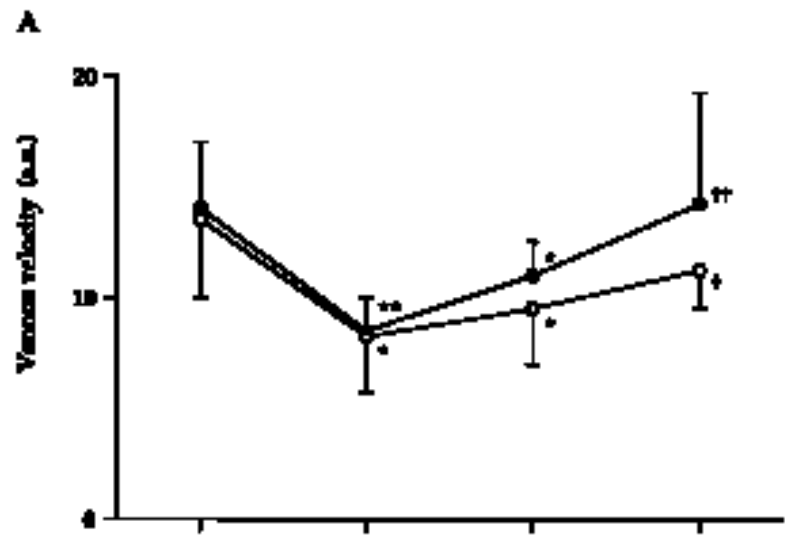

E

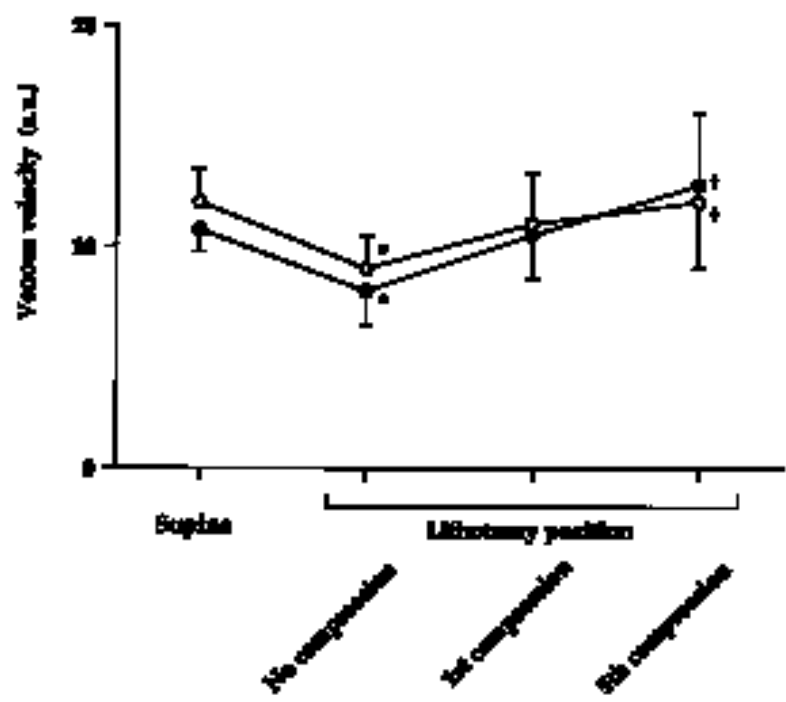

FIGURE 2 Changes in maximum femoral venous flow velocities with the conventional lithotomy positioning device (LPD; A) or with a new LPD (B) during compression with rapid (closed circles) and standard (open circles) intermittent pneumatic compression devices. Data are expressed as mean $\pm \mathrm{SD}, n=6$ at each point [arbitrary units; a.u.]. ${ }^{*} P<0.05 ;{ }^{*} P<0.01$ vs control; $\dagger P<0.05$ vs lithotomy position without compression.

to $97 \%$ and $108 \%(P<0.05)$ of the control value and to $92 \%$ and $104 \%(P<0.05)$ of the control value during compression, respectively. There was no significant difference between the effects of rapid and standard IPC on flow velocity in any situation.

Discussion

Formation of a deep vein thrombus in the lower extremities can lead to lethal pulmonary thromboem- bolism. Control of blood coagulability and maintenance of sufficient venous blood flow in the lower extremities are important to prevent thrombus formation. Although anticoagulants are effective in reducing the risk of thrombus formation, adequate control of blood coagulability is difficult and associated with adverse effects. Prevention of venous stasis should be effective and relatively safe. An IPC device has virtually no adverse effects and offers an interesting alternative to anticoagulant therapy in patients who have a high risk of bleeding.

The conventional lithotomy position is anticipated to induce blood stasis in the lower extremities, as shown in our study (Figure 2). A new LPD (Levitator) that supports the lower extremities at the heels and calves without knee compression has become available commercially. This device was designed to minimize the effect of the lithotomy position on blood flow in the lower extremities. As expected, our results showed that this device caused less reduction in femoral venous blood flow than did conventional positioning with knee compression. Thus, this LPD might be useful in patients who are at high risk of deep venous thrombosis.

Recent studies assessing the efficacy and safety of foot impulse technology in the prevention of venous thrombosis have shown promising results. ${ }^{11,12}$ In a pilot study, a foot pump was shown to be more effective than lowdose heparin in the prevention of venous thrombosis following total hip replacement. ${ }^{11}$ A more recent study demonstrated that low-molecular-weight heparin prophylaxis was superior to foot compression in the prevention of postoperative thrombosis in orthopedic patients. ${ }^{13}$ Elliott et al. ${ }^{6}$ reported that calf-thigh sequential pneumatic compression prevents deep-vein thrombosis more effectively than does plantar venous IPC after major trauma without lower extremity injuries. Other investigators, however, have reported that there are no differences in the effects of calf and thigh length pneumatic compression systems and intermittent plantar compression on prevention of venous thrombosis. ${ }^{7-9}$ Our study showed that both rapid and standard IPC significantly increased femoral venous blood flow in the supine and in the lithotomy position and that the effects of these IPC devices were similar. Foot/leg compression by IPC devices may have some effect on blood coagulability by increasing sheer stress on platelets and endothelial cells. ${ }^{14}$ Changes in fibrinolytic activity due to the use of an IPC device may be involved also. Some investigators have reported that an IPC device increased fibrinolytic activity, ${ }^{15,16}$ while others reported that an IPC device had no effect. ${ }^{17,18}$ Further investigations using more reliable coagulation/fibrinolysis monitors are needed to clarify this point. 
In conclusion, a new LPD that does not require popliteal fossa compression has less effect on femoral venous flow velocity than does conventional positioning. Rapid and standard IPC are useful for maintaining venous flow of the lower extremities in the lithotomy position.

\section{References}

1 McLeod RS. The risk of thromboembolism in patients undergoing colorectal surgery. Drugs 1996; 52(Suppl 7): 38-41.

2 Kakkos SK, Szendro G, Griffin M, Daskalopoulou S-S, Nicolaidou $A N$. The efficacy of the new SCD response compression system in the prevention of venous stasis. J Vasc Surg 2000; 32: 932-40.

3 Millard JA, Hill BB, Cook PS, Fenoglio ME, Stablgren $L H$. Intermittent sequential pneumatic compression in prevention of venous stasis associated with pneumoperitoneum during laparoscopic cholecystectomy. Arch Surg 1993; 128: 914-9.

4 Woolson ST. Intermittent pneumatic compression prophylaxis for proximal deep venous thrombosis after total hip replacement. J Bone Joint Surg Am 1996; 78: $1735-40$.

5 Bradley JG, Krugener GH, Jager HJ. The effectiveness of intermittent plantar venous compression in prevention of deep venous thrombosis after total hip arthroplasty. J Arthroplasty 1993; 8: 57-61.

6 Elliott CG, Dudney TM, Egger M, et al. Calf-thigh sequential pneumatic compression compared with plantar venous pneumatic compression to prevent deepvein thrombosis after non-lower extremity trauma. J Trauma 1999; 47: 25-32.

7 Soderdabl DW, Henderson SR, Hansberry KL. A comparison of intermittent pneumatic compression of the calf and whole leg in preventing deep venous thrombosis in urological surgery. J Urol 1997; 157: 1774-6.

8 Anglen JO, Bagby C, George R A randomized comparison of sequential-gradient calf compression with intermittent plantar compression for prevention of venous thrombosis in orthopedic trauma patients: preliminary results. Am J Orthop 1998; 27: 53-8.

9 Wood KB, Kos PB, Abnet JK, Ista C. Prevention of deep-vein thrombosis after major spinal surgery: a comparison study of external devices. J Spinal Disord 1997; 10: 209-14.

10 Flam E, Berry S, Coyle A, Dardik H, Raab L. Blood-flow augmentation of intermittent pneumatic compression systems used for prevention of deep vein thrombosis prior to surgery. Am J Surg 1996; 171: 312-5.

11 Fordyce MJF, Ling RSM. A venous foot pump reduces thrombosis after total hip replacement. J Bone Joint Surg Br 1992; 74: 45-9.
12 Turner GM, Cole SE, Brooks JH. The efficacy of graduated compression stockings in the prevention of deep vein thrombosis after major gynaecological surgery. $\mathrm{Br}$ J Obstet Gynaecol 1984; 91: 588-91.

13 Blanchard J, Meuwly J-Y, Leyvraz P-F, et al. Prevention of deep-vein thrombosis after total knee replacement. Randomised comparison between a low-molecularweight heparin (nadroparin) and mechanical prophylaxis with a foot-pump system. J Bone Joint Surg $\mathrm{Br}$ 1999; 81: 654-9.

14 Dai G, Tsukurov O, Orkin RW, Abbott WM, Kamm $R D$, Gertler JP. An in vitro cell culture system to study the influence of external pneumatic compression on endothelial function. J Vasc Surg 2000; 32: 977-87.

15 Inada K, Koike S, Shirai N, Matsumoto K, Hirose M. Effects of intermittent pneumatic leg compression for prevention of postoperative deep venous thrombosis with special reference to fibrinolytic activity. Am J Surg 1988; 155: 602-5.

16 Petäjä J, Myllynen P, Myllylä G, Vabtera E. Fibrinolysis after application of a pneumatic tourniquet. Acta Chir Scand 1987; 153: 647-51.

17 Christen $\Upsilon$, Wütschert R, Weimer D, de Moerloose P, Kruithof EKO, Bounameaux $H$. Effects of intermittent pneumatic compression on venous haemodynamics and fibrinolytic activity. Blood Coagul Fibrinolysis 1997; 8: 185-90.

18 Cahan MA, Hanna DJ, Wiley LA, Cox DK, Killewich $L A$. External pneumatic compression and fibrinolysis in abdominal surgery. J Vasc Surg 2000; 32: 537-43. 